Supplement of Clim. Past, 15, 153-168, 2019

https://doi.org/10.5194/cp-15-153-2019-supplement

(C) Author(s) 2019. This work is distributed under

the Creative Commons Attribution 4.0 License.

(c) (1)

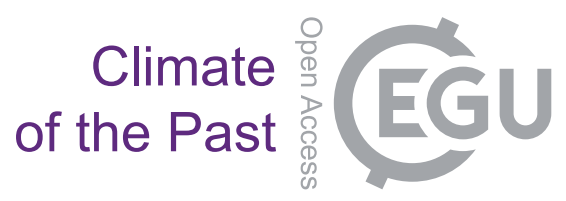

Supplement of

\title{
Heinrich events show two-stage climate response in transient glacial simulations
}

Florian Andreas Ziemen et al.

Correspondence to: Florian Andreas Ziemen (florian.ziemen@mpimet.mpg.de)

The copyright of individual parts of the supplement might differ from the CC BY 4.0 License. 


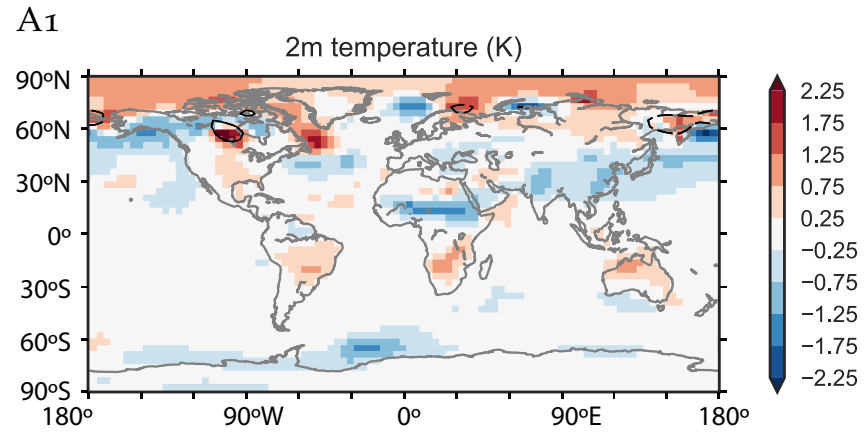

A2

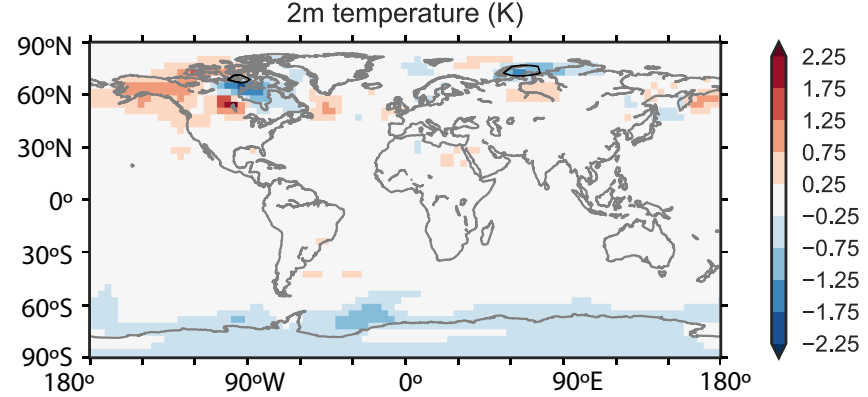

B1

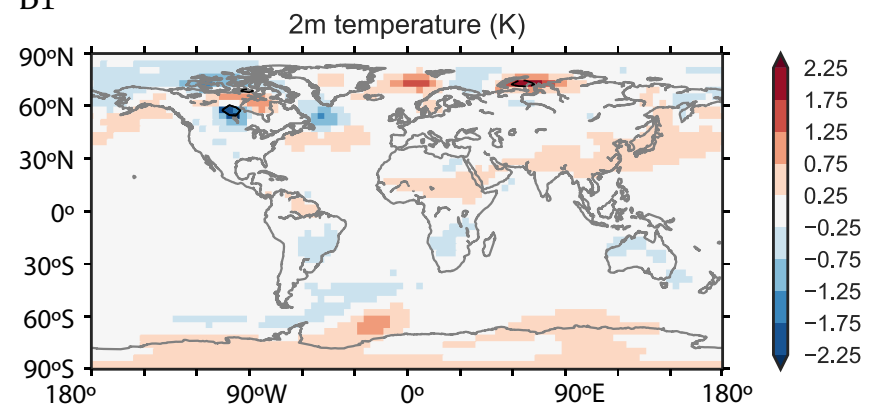

CI

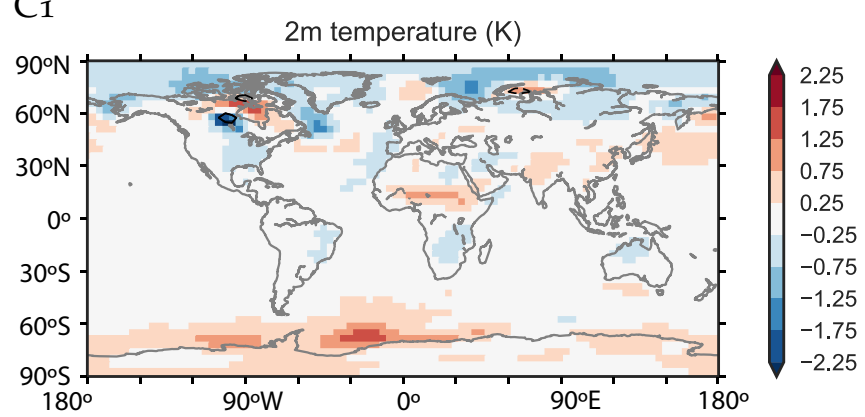

Figure 1: $2 \mathrm{~m}$ air temperature differences of the pre-surge states with regard to their mean. The overlays mark the elevation differences seen by ECHAM at $250 \mathrm{~m}$ levels. Dashed lines mark lower elevations. All temperature and elevation differences are small enough to consider the different Heinrich event background states as similar enough for the composite. 
A1 Surface elevation difference $(m)$

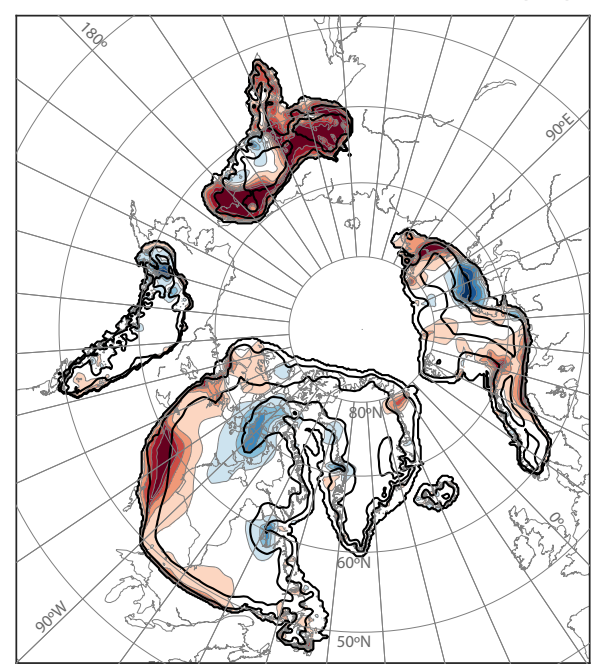

B1 Surface elevation difference (m)

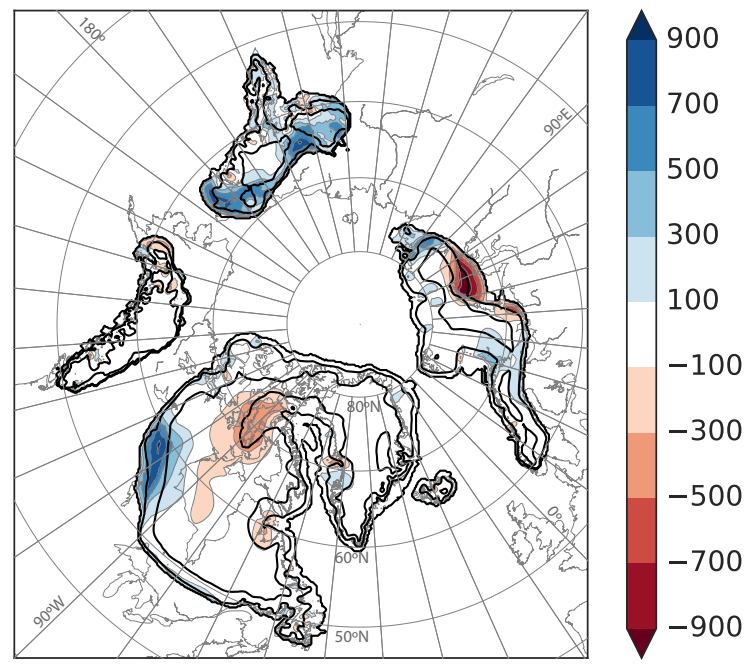

A2 Surface elevation difference (m)

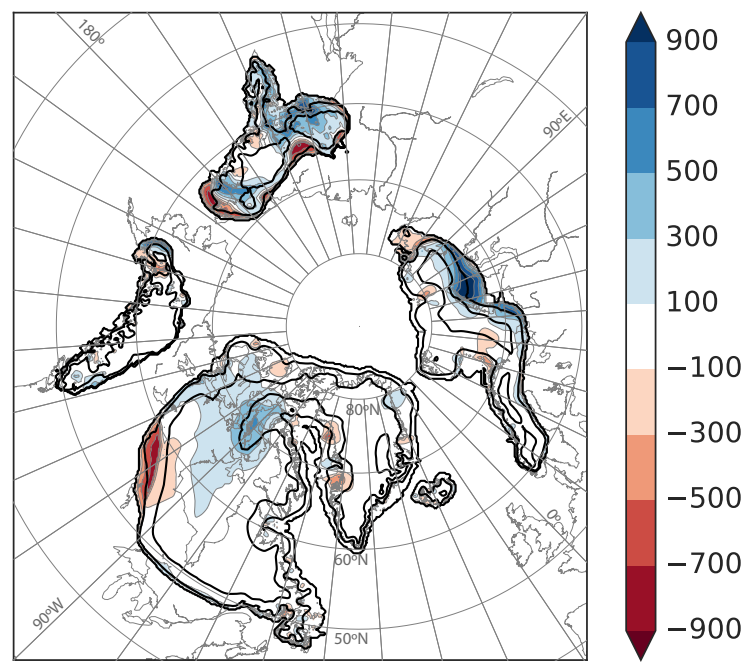

$\mathrm{C}_{1} \quad$ Surface elevation difference (m)

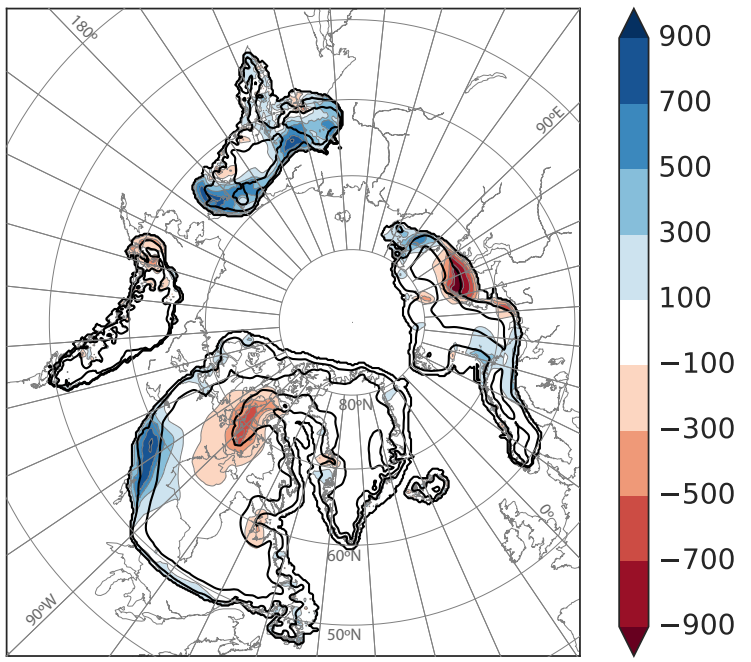

Figure 2: Ice sheet elevation differences of the pre-surge states with regard to their mean. The overlays mark the elevation in the reference run. All elevation differences are small enough to consider the different Heinrich event background states as similar enough for the composite. 
(a)
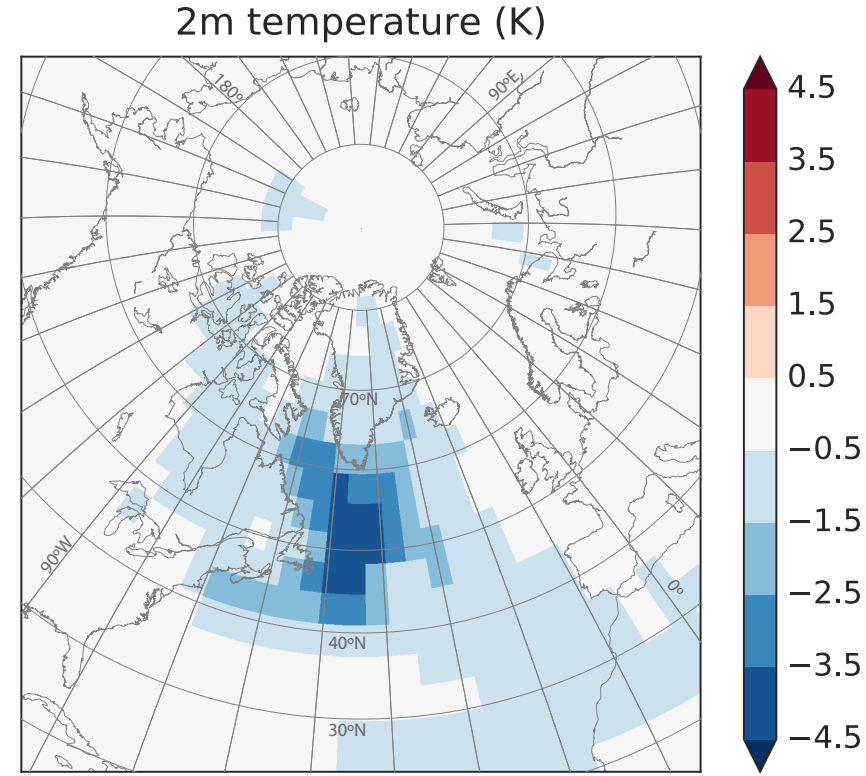

(b)
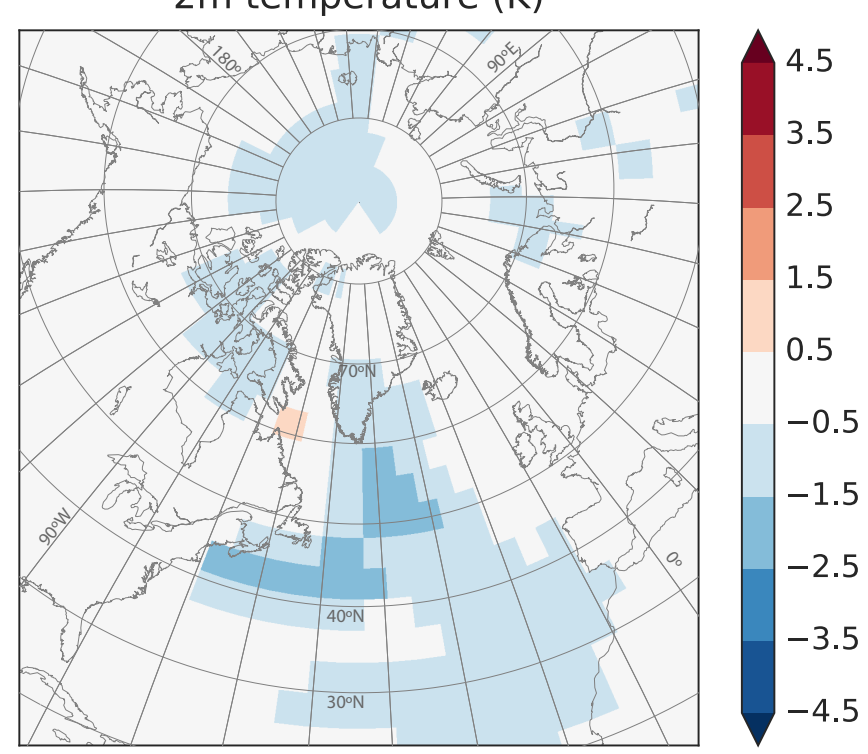

(c)

$2 \mathrm{~m}$ temperature $(\mathrm{K})$
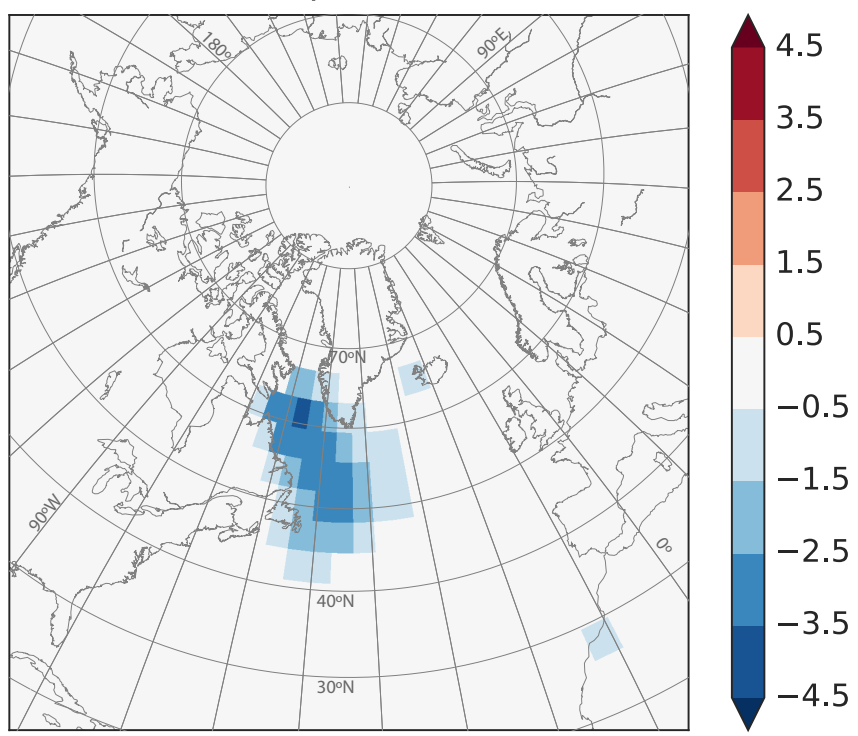

Figure 3: Influence of the latent heat flux ascribed to ice discharge experiments with o.1 Sv freshwater hosing in Hudson Strait. a) 2m air temperature change in a hosing experiment with latent heat effect. b) $2 \mathrm{~m}$ air temperature change in a hosing experiment without latent heat effect. c) Contribution of the latent heat effect to the $2 \mathrm{~m}$ air temperature changes. Calculated as $a)-b$ ) These experiments were based on an climate-only experiment with glacial maximum boundary conditions as described in Ziemen et al. (2014), with fixed ice sheets and ice discharge and melt rates. The data is averaged over centuries 3-5 of the hosing experiments and a matching control run. 


\section{References}

Ziemen, F. A., Rodehacke, C. B., and Mikolajewicz, U.: Coupled ice sheet-climate modeling under glacial and pre-industrial boundary conditions, Clim. Past, 10, 1817-1836, DOI: 10.5194/cp-101817-2014, URL http://www.clim-past.net/10/1817/2014/, 2014 . 